\title{
The Use of Cryo dehydratated Animal Anatomical Segments for Veterinary Anatomy Teaching
}

\author{
Ana Luisa S Valente ${ }^{1 *}$, Lygia Almeida ${ }^{1}$, and Jose Eduardo Dornelles ${ }^{2}$ \\ ${ }^{1}$ Department of de Morfologia Universidade Federal de Pelotas, Brazil \\ ${ }^{2}$ Department of de Zoologia e Genetica Universidade Federal de Pelotas, Brazil
}

Submission: July 11, 2017; Published: March 28, 2018

*Corresponding author: Ana Luisa Schifino Valente, Instituto de Biologia Universidade Federal de Pelotas, Campus Universitario S/N-CEP 96160-000 capão do Leao, RS, Brazil, CP 354, Tel:+555332757339/7323; Email: schifinoval@hotmail.com

\begin{abstract}
The veterinary anatomy teaching in the Veterinary Schools around the world has been supported by diverse kinds of innovations such as digital resources and applications, being the use of cadaver's dissections very limited. In the present study, the use of cryo dehydrated anatomical pieces of musculoskeletal structures from large and small animals were experimented for five years and the vantages and advances were computed. The material was prepared using a fixation of fresh material with $10 \%$ formalin followed by dissections and freezing-unfreezing sequences until completely be dried. Paints were performed to give a natural appearance. The material produced, including complete limbs from large and small animals had a good quality and preservation of the structures such as ligaments, muscle mass, tendons and apo euroses. The topographical relationships were perfectly maintained and the pieces revealed to be a reliable material for the practical of musculoskeletal anatomy. The method used was easy applied, very cheap, of stress-free manipulation and storage and due to its high durability reduced the discharge of biological wastes and chemical products. The students were very friendly to this kind of material what reflected in high coefficient of approval during the practical examinations. The experience of create additional assignment to teaching how to prepare the material was successful and have been a great integration opportunity to students from last years of the course work together and share experiences with the beginners, when they check anatomic contents considering the applicability in clinic and surgical practices.
\end{abstract}

Keywords: Veterinary anatomy teaching; Criodehydration technique; Cadaver conservation

\section{Introduction}

It is unquestionable that the recognition of gross anatomical structures and their normal aspect and positioning in healthy animals is basic in the veterinary formation. Most of Veterinary Schools around the world have at least two teaching assignatures at the curricula about gross anatomy. Historically, the experience in this area counted with the use of cadaver's dissections but this subject has been much discussed [1,2] and not more employed in most universities. Although some studies suggest that dissection, coupled with associated educational activities, is an effective pedagogical strategy for learning $[3,4]$, nowadays, the use of digital ways to explain this subject is more frequent to describe muscular structures [5], being the cadaver's use very limited. Unlike osteological material, that has a permanent character and is available in the laboratories and museums where is stored with relative easiness, muscular structures are expensive to preserve. Many techniques are known to keep this kind of material for long time [6], but most of them implies in high cost of maintenance in suitable tanks. Digital lectures [7] and three-D applications [8] based on reconstructions of series of drawings are very popular and helpful among students because the applications allows to put or remove layer of muscles and they provide basic knowledge about spatial anatomy [9] but, in most of them the interpolation of data is far of the natural structure and students have difficulty when in front an anatomical piece in the laboratory. Synthetic models are also useful, but have an expressive cost of acquisition and are not so attractive and interesting to the student as the laboratory practices. The gross anatomical dissection is a crucial part of the education of veterinarians because it takes important manual skills, anatomic knowledge as well as an understanding of spatial relationships of structures and organs of the body.

Reasons because practices with cadavers are more scarce includes the low availability of dead animals intended to this kind of practices once animals are protected by international laws that forbid the euthanasia for education or investigation studies, the use of toxic substances to preserve the material, and need of appropriated facilities to storage the anatomic pieces, mainly treating of large animals, in which the discharges of biological fluids and of conserving may a terrible source of environmental contamination.

At South Brazil, many veterinary schools are focused mainly in farm animals due to the expressive impact of the cattle farming in the country economy. Other areas of veterinary medicine, including large animals, are also imperative, such as the equine 
clinics and sheep and swine productions. At Federal University of Pelotas, classes of veterinary anatomy are offered in the first and second semesters of the curriculum, and composed by a total of 136 hours each one, with half charge in laboratory practices. The assignment entitled Anatomy of Domestic Animals I (ADA I) receive annually about 160 academics and has focus in the musculoskeletal structures, being comparative among domestic species including both, large and small animals. Parts of bovine carcasses are obtained by donation from slaughterhouses located near the University, but just corporeal segments without economic value are available. Other source of biological material is the Animal Hospital of the university, where the bodies of dead animals (small and large size) free of infectious and zoonotic diseases are carried to the Anatomy Sector to classes use. Given it is a public institution the university has limited financial resources, including those destined to buy synthetic models to contemplate all students and, a small number of technicians to support the laboratories. Considering the high number of students supported and the suitable quantities of material in the labs, the logistics is compromised due the space to storage and posterior discharging of cadavers. To become viable for classes including until 75 students simultaneous at the laboratory, since the two last decades, we have applied and developed anatomical techniques10 to solve these problems. This work has as aim to present these techniques as well as to show how they have worked which good results in the veterinary teaching.

\section{Material and Methods}

Fresh cadavers from equines, bovines and dogs were used in present study, the carcasses were obtained from animals that dead from the Animal Hospital from University of Pelotas. Cryodehydration technique described by previous work [10] was incremented with paintings and resin layers, being produced anatomical pieces with superficial and deep muscle dissections. A quick pass-by-pass is exposed here:

a. Fresh carcasses were used immediately or frozen at -20 ${ }^{\circ} \mathrm{C}$ for further studies;

b. Carcasses with complete integrity (i.e., without missing parts and without skin without sections) were preferably perfused with $10 \%$ formalin dilution using the external carotid artery only on one side of the neck. The solution was spread on the carcass through the vascular system using the pressure produced by raising a deposit of formalin solution $2.5 \mathrm{~m}$ from the ground. The expected positioning of the head and limbs should be provided prior to this step because the fixed tissues are difficult to move after the process. The infusion is complete when muscle stiffness is verified and a foamy discharge is released from nares.

c. When only body parts are available, multifocal perfusion through muscle tissues and joint cavities is conducted using manual injection with needles attached to $50 \mathrm{ml}$ syringes. The infusion is complete when, after all the tissues are exposed to the fixative solution, including the deeper ones. In addition, the material should be immersed in $10 \%$ formalin tanks within the next 48 hours

d. In both cases, the carcasses are covered with plastic material and stored at room temperature (8-220C) during 24 to $48 \mathrm{~h}$.

e. Carcasses are washed with tap water and dissected as a convenience of the proposed class, using traditional anatomic dissections techniques for musculature visualization.

f. At this stage, the anatomical pieces can be used in some lab classes, taking account the partial volatilization of the formalin, with could be irritant to eyes and nose mucosa.

g. Dissected anatomical pieces pass by at least twenty cryodehydration sequences, including freezing at -200C and unfreezing at 10 to $220 \mathrm{C}$, air relative humidity around 70 $80 \%$. After that, the material is kept out of the freezer until its complete drying, with is verified when a fine paper towel compressed in the structures is removed completely dry.

h. A new careful debriding of tissues using the bistoury to produce scrapping and removal of dry fascia and perimysium will expose better the muscular fibers. Removals of periosteum in some parts are also need and will grant a better recognition of the structures.

i. Finally, structures can be painted with gouache painting combination colors closer to the natural appearance of a fresh tissue. Three coatings of gum composed by acetate of polyvinyl are used. First coating with $50 \%$ of dilution in water and the next two using the pure glum. Drying time is about 12 hours.

\section{Teaching application of the Material}

For ten semesters, this kind of material have been used in the ADA I and was freely available at labs, which were opened at least 2 hours daily for extra-class study. In some pieces, structures were permanently labeled. Other kind of gross anatomical pieces included those fixed in formalin and cryodehydrated metameric sections.

The presence of students in the labs was monitored as well as the use that they made of the material and the general conservation of the anatomical pieces. The performance of the students in subsequent examinations was computed.

\section{Results}

Dehydrated anatomical pieces completed about $70 \%$ of the material used in practical classes of veterinary anatomy during the study. Some students complementary used digital applications but synthetic models were not available by the university. The material produced, including complete limbs from large and small animals had a good quality and conservation of the structures such as ligaments, muscle mass, tendons and aponeurosis. The topographical relationships are perfectly maintained and the material revealed to be a reliable 
for practical classes of musculoskeletal anatomy. Some regions of clinical concernment, as ligaments from distal end of equine and bovine limbs, including all sesamoids suspensory apparatus were very distinguishable. Thorax and abdomen of dogs also provide excellent visualization of the muscles. All dehydration pieces were storage in cabinets with glass door (Figure 1) and are freely used on laboratory tables by the students. Anatomical pieces are odourless, dried and resistant to the touch. The students are friendly to use it because they are very didactic, easy manipulation and learning. The frequency in the practical laboratory was increased even when technicians were not available to provide material. Topics with a good visualization of structures using cryodehidrated anatomical pieces.

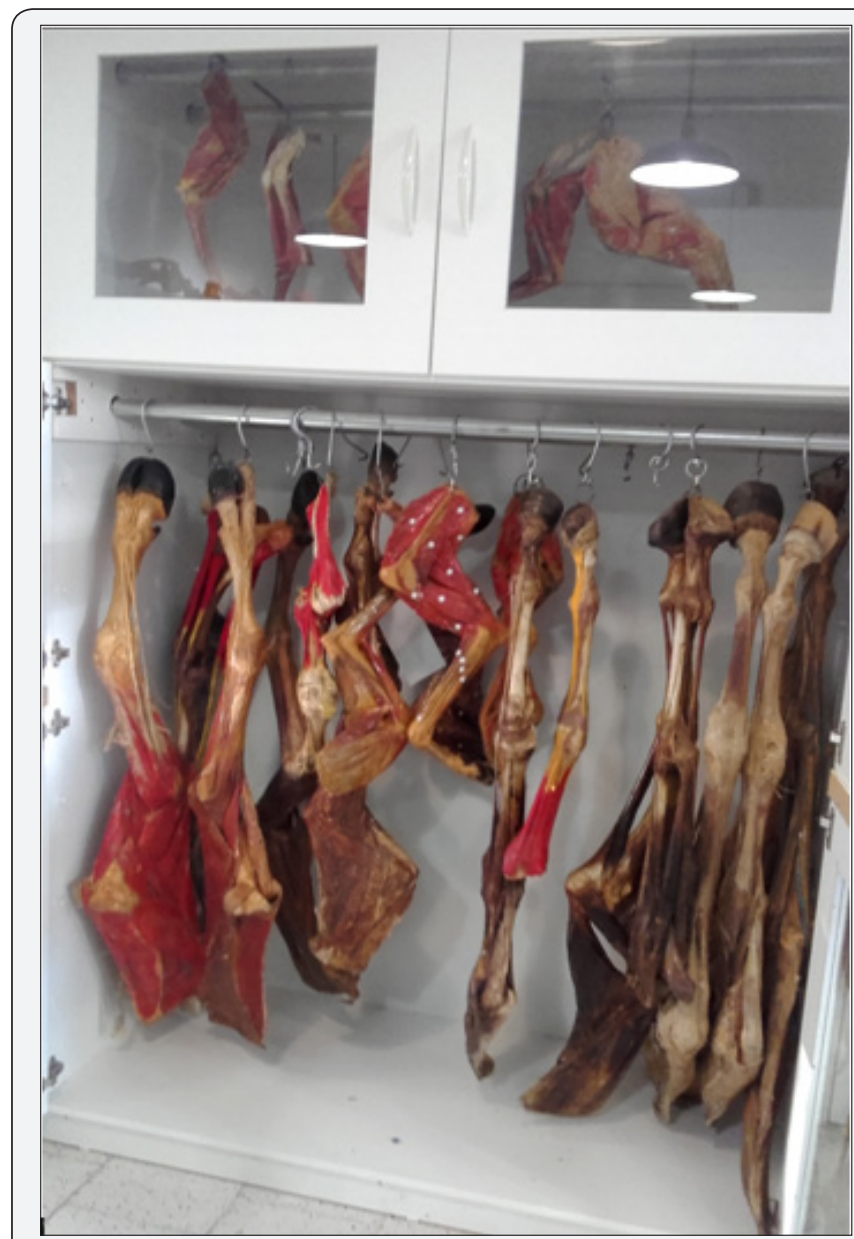

Figure 1.Dehydration thoracic limbs (bovine, equine and canine) storage in cabinets at laboratory.

\section{Head of equine and dog}

We used to divide using an electric band saw, the head in left and right antimeric sections, with allowed visualization of strutures in the medial and lateral aspect. In the medial aspect, it is appreciable to visualize the encephalon, ethmoid turbinates, nasal turbinates, hard palate, tongue, pterygoid muscle, parts of hyoid apparatus, digastric muscle (in horse). From lateral aspect is visualized most of face musculature, deep or superficial structures according to the previous dissections (Figure 2).

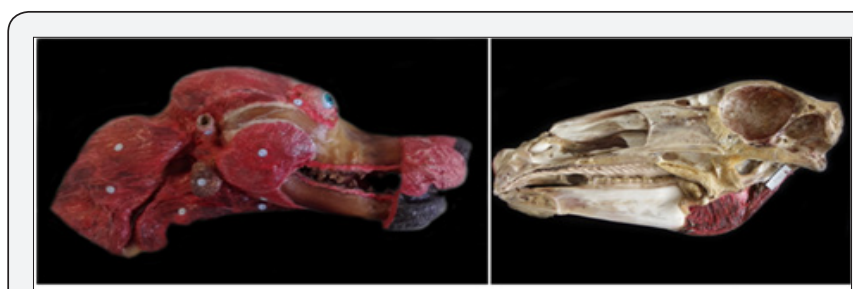

B

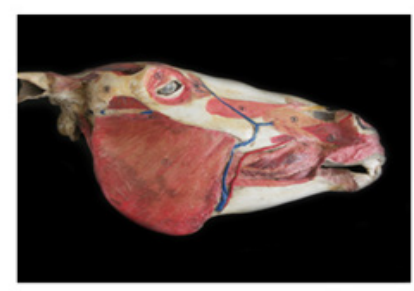

Figure 2 : Cryodehydrated heads of dog (A) and horse, B lateral view and $\mathrm{C}-$ medial view.

\section{Limbs of equine, bovine and dog}

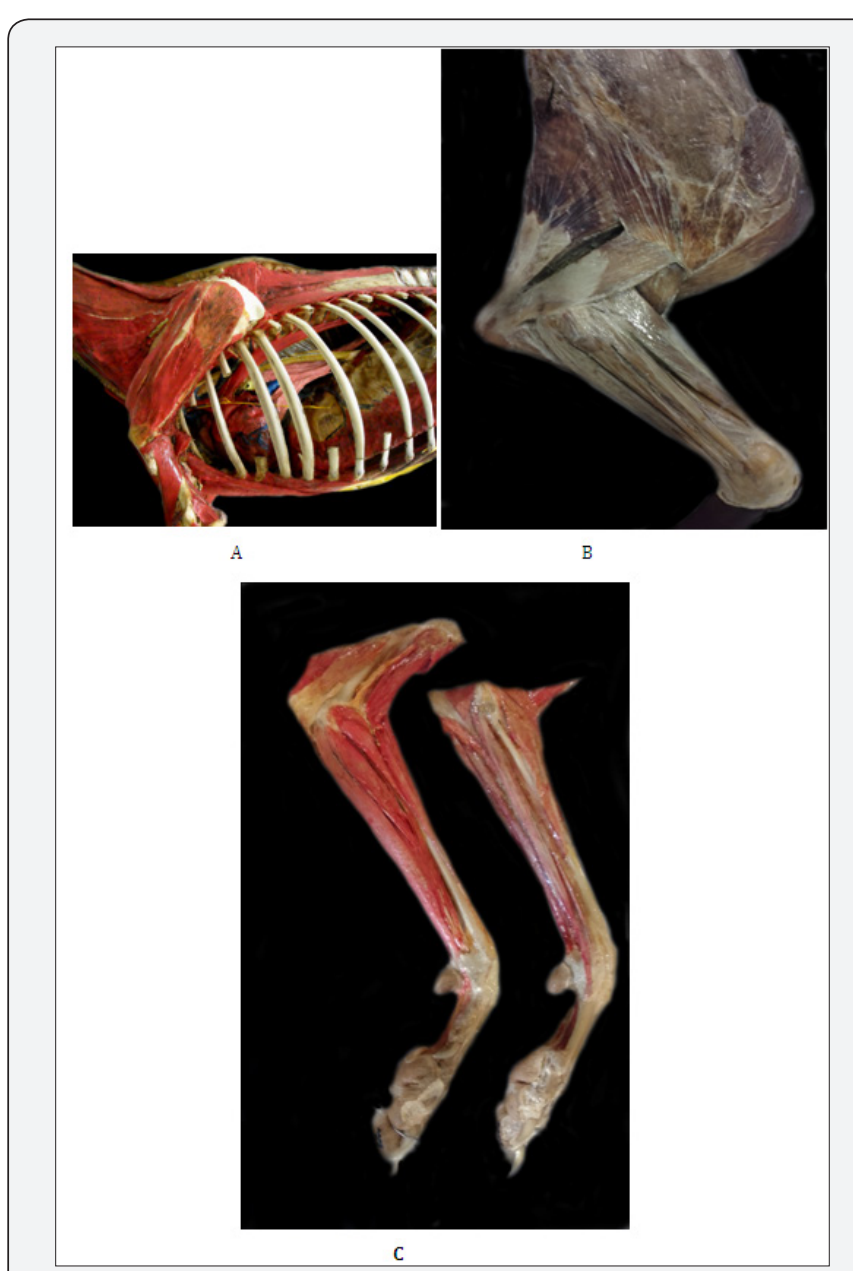

Figure 3. Cryodehydrated anatomical pieces used in gross anatomy teaching. A - Deep dissection of horse thorax and thoracic limb. B. Thoracic limb of a bovine without paint. C Forearm of dog (medial -at left and lateral views -at right) 
The relationships among muscles and articular structures are clearly verified (Figure 3). Hooves were also sectioned and internal components and their exact positioning and syntopy can be easily studied (Figure 4).

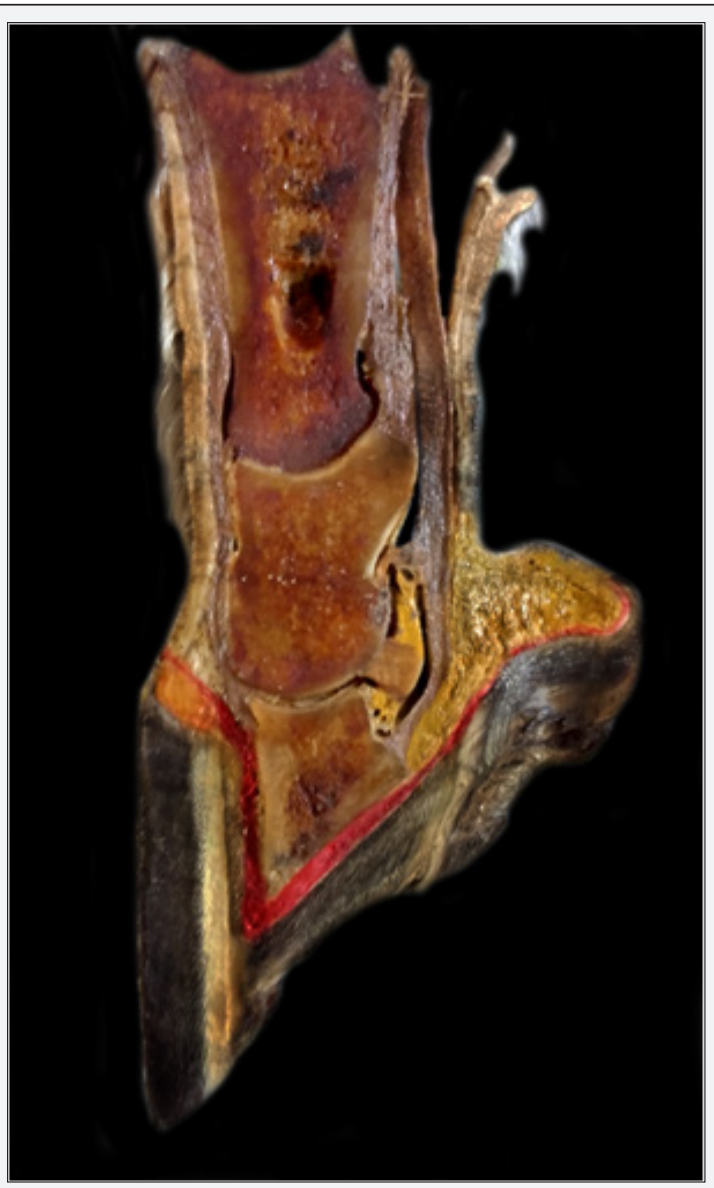

Figure 4. Cryodehydrated sagittal section of the hoof of equine.

\section{Thorax and abdomen of small animals}

These corporal segments were also studied in left and right antimeric sections and internal organs were removed to allow highlight to the muscles. Dogs of medium size were chosen and most of accumulated fat between muscles was manually removed prior dehydration. In general, material with less than $2 \mathrm{~cm}$ of thickness was more quickly dehydrated. As the most of animals used dead due to traumatic injuries, the use of hydrogen peroxide $20 \mathrm{~V}, 50 \%$ diluted in water was need to promote cleaning in surfaces with blood impregnation. In practices classes, the teaching of the muscles of the trunk was also performed using wet pieces fixed with formalin what allowed the better understanding the layers of muscles.

\section{Discussion}

Cryodehidrated anatomical pieces from the digestive tract have been applied in the some veterinary schools from Brazil [11] with satisfactory results in the anatomical teaching [12]. The methodology explained in the present study for musculoskeletal structures of large and small animals has been applied with success in the veterinary anatomy teaching at Federal University of Pelotas for more than 25 years, but the teaching experience have not evaluated and published. The great contributions of employing the cryo dehydrated material as a teaching tool are: the low cost, high durability, easy handling and storage, low toxicity, long term reduction of environmental contamination by biological and chemical wastes and the attractive effect on the students. Similar material is also produced using a plastination process $[13,14]$ in which the water and fat are replaced by certain plastics, yielding specimens that can be touched, do not smell or decay, and even retain most properties of the original sample [11]. However, this process is not available in most Veterinary Schools around the world due to high cost of execution, once require specific equipment and chemical components. The cryo dehydration technique used in the present work have a low cost, requiring just formalin, domestic freezer (for small animals) and artisanal material for completion, easily found in hardware stores. Once prepared, the anatomical material can be stored for long time (more than 20 years) in places free of humidity and decomposers insects (coleopterans). This reduces the logistic and costs to keep large formalin tanks to store body parts. As water is lost during the process, there is a reduction of approximately $60 \%$ of the original weight of the material which became it slighter and of easy handling [10]. During the practical classes and studies extra-classes, the students are not exposed to volatile toxic substances becoming this moment more long and comfortable. Due its great durability, the same piece can be used for several years without need of replacement, which minimizes the probability of environment contamination. Lastly, the material produced in colors or in pale tones (without paints) arouses interest in students with is expressed in the low disapproval coefficients ( 8 to $11 \%$ ) observed in the practical examinations.

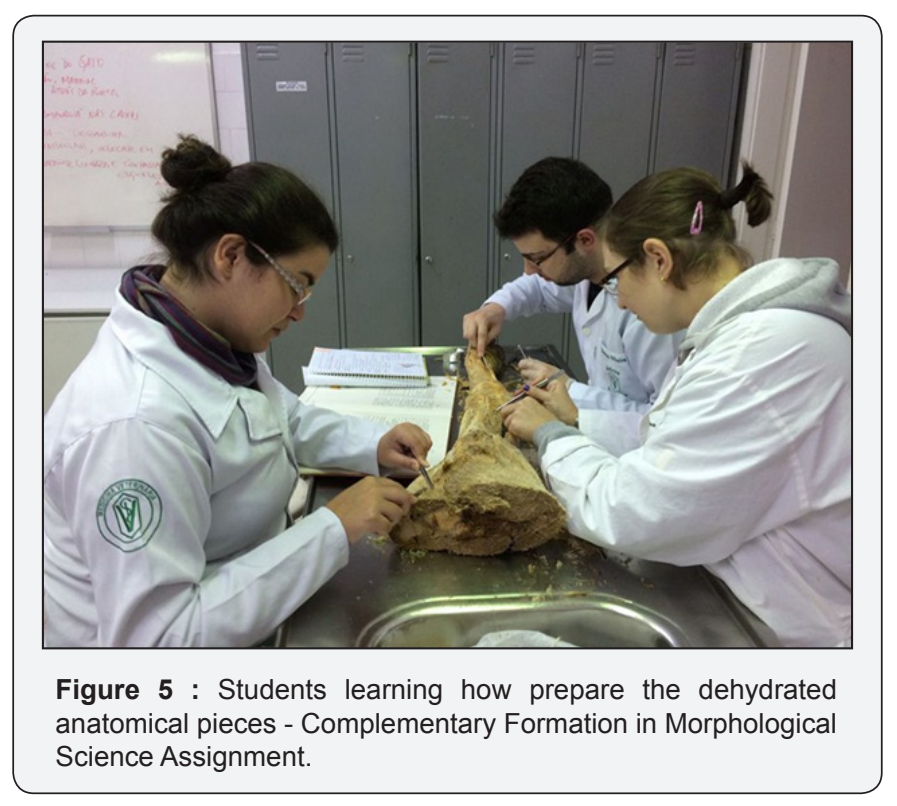

Actually we counted just with a technician to general activities in the sector that receive also students of zootechny 
course, in a total of 600 students annually. Little skilled laborto produce the material is required. As the interest of students and curiosity in to know how to prepare the material have increasing, the Anatomy Sector decided to create an optional assignment with maximum 10undergraduates to provide specific training (Figure 5). Two classes are planned each year and, year after year, they have increasing the anatomical collection available to next students, sequentially. There is a great integration opportunity to students from last years of the course to work together and share experiences with the beginners, when they check anatomic contents considering the applicability in clinics and surgical practices.

\section{Acknowledgment}

We are grateful to the students of the Complementary Formation in Morphological Science Assignment, whose have been collaborating in preparing anatomical pieces. Thanks go to anonymous reviewer for the patience to help the English language in this manuscript.

\section{References}

1. Gareth JD (1997) Reassessing the importance of dissection: a critique and elaboration. Clinical Anatomy 10(2): 123-127.

2. Nwachukwu C, Lachman N, Pawlina W (2015) Evaluating dissection in the gross anatomy course: correlation between quality of laboratory dissection and students outcomes. Anatomical sciences education 8(1): 45-52

3. Pizzimenti MA, Pantazis N, Sandra A, Hoffmann DS, Lenoch S, et al. (2016) Dissection and dissection associated required experiences im- prove student performance in gross anatomy: Differences among quartiles. Anat Sci Educ 9(3): 238-46.

4. Ghosh SK (2017) Cadaveric dissection as an educational tool for anatomical sciences in the $21^{\text {st }}$ century. American Association of Anatomists, 10: 286-299.

5. Moore J (2017) Muscle Motion.3D4Medical.

6. Hildebrand M (1968) Anatomical Preparations. University of California Press, Berkeley and Los Angeles pp.100.

7. Singh A, Min AK (2017) Digital lectures for learning gross anatomy: a study of their efficacy. Korean J Med Educ 29: 27-32.

8. Hoyek N, Collet C, Di Rienzo F, De Almeida M, Guillot A (2014) Effectiveness of three-dimensional digital animation in teaching human anatomy in an authentic classroom context. Am Assoc Anatom 7: 430-437.

9. Skrabe VE (2018) Ilustracoes Biomedicas Tools for learning and teaching Veterinary Anatomy.

10. Teixeira A, Teixeira AF, Guarenti VPJ (1990) Desidratacao de musculos no preparo depecas anatomicas Rev bras Cien Morfol. 7/8(2/1): 45-47.

11. Kremer R, Schubert JM, Bonfiglio NS (2011) Criodesidratacao de visceras do canal alimentar no preparo de pecas anatomicas para estudo veterinario. Pub Vet, Londrina 5(13): 1-7.

12. Cury FS, Censoni JB, Ambrosio CE (2013) Tecnicas anatômicas no ensino da pratica de anatomia animal. Pesquisa Veterinária Brasileira 33(5): 688-696.

13. Latorre RM, Garcia Sanz MP, Moreno M, Hernandez F, Gil F, et al. (2007) How usefull is plastination in learning anatomy? J Vet Med Educ 34: 172-176.

14. Ravi SB, Bhat VM (2011) Plastination: A novel, innovative teaching adjunct in oral pathology. J Oral Maxillofac Pathol 15: 133-137.

\section{Your next submission with Juniper Publishers will reach you the below assets}

- Quality Editorial service

- Swift Peer Review

- Reprints availability

- E-prints Service

- Manuscript Podcast for convenient understanding

- Global attainment for your research

- Manuscript accessibility in different formats

( Pdf, E-pub, Full Text, Audio)

- Unceasing customer service

Track the below URL for one-step submission https://juniperpublishers.com/online-submission.php 